ISSN 1981-416X

Licenciado sob uma Licença Creative Commons

(c) (1)

\title{
Os Saberes para ensinar e saberes a ensinar aritmética na Escola de Aprendizes Artífices de Santa Catharina
}

The knowledge for teaching and the knowledge

to teach arithmetics in the Escola de Aprendizes Artifices de Santa Catharina

Los saberes para enseñar e los saberes

a enseñar aritmética en la Escola de Aprendizes Artífices de Santa Catharina

\section{Cleber Schaefer Barbaresco, David Antonio da Costa*}

\section{Resumo}

A Escola de Aprendizes Artífices de Santa Catharina foi uma importante instituição de ensino profissional que oferecia o ensino elementar gratuito. Com isso, o propósito deste artigo é investigar saberes relacionados aos afazeres pedagógicos do ensino de aritmética do curso primário desta Escola. Para tanto, serão analisados os relatórios do Serviço de Remodelação do Ensino Profissional Técnico da década de 1920 e do livro Arithmetica Elementar Illustrada, 92a edição, de 1922, de Antônio Bandeira Trajano. O ferramental teórico-metodológico

*CSB: Graduado em Matemática, e-mail: cleber.s.b@posgrad.ufsc.br

DAC: Doutor em Educação Matemática, e-mail: david.costa@ufsc.b 
utilizado para análise dos documentos foram os saberes para ensinar e saberes a ensinar desenvolvidos pela Equipe de Pesquisa em História Social da Educação (ERHISE) a partir de seus estudos sócio-históricos vinculados à História Cultural. Os relatórios do Serviço de Remodelação sugerem propostas que resultam em mudanças significativas no ensino profissional como, por exemplo, a adoção de uma única estrutura curricular e um inventário de livros didáticos que deveriam ser adotados pelas unidades escolares espalhadas pelo País. Desse modo, concluímos que os saberes para ensinar e saberes a ensinar aritmética foram instituídos a partir da expertise de João Luderitz, coordenador do Serviço de Remodelação, e sua equipe. No que diz respeito aos saberes para ensinar aritmética, o método intuitivo foi a referência. Já os saberes a ensinar aritmética foram reestruturados com base na proposta do Serviço de Remodelação afastando-os do seu propósito inicial assistencialista voltado apenas para a alfabetização, dando assim um status mais científico.

Palavras-chave: Escola de Aprendizes Artífices de Santa Catharina. Ensino de Aritmética. Ensino Profissional. Saberes para ensinar. Saberes a ensinar.

\section{Abstract}

The Escola de Aprendizes Artifices de Santa Catharina was an important institution of professional education that offered the gratuitous elementary school. Thereby, the purpose of this article is to investigate the knowledge related to the pedagogical tasks of the arithmetic teaching of the primary course in this School. For this, we'll analyze reports of the Remodeling Service of the Technician Professional Education of the decade of 1920 and the book Arithmetica Elementar Illustrada, 929 edition, of 1922, by Antônio Bandeira Trajano. The theoretical-methodological tools used for the analyses of the documents were the knowledge for teaching and the knowledge to teach developed by the Team of Research in Social History of Education (TRSHE) from their social-historical studies linked to the Cultural History. The reports of the Remodeling Service suggest proposals that resulted in significant changes in the professional education such as, for example, the introduction of a single curricular structure and an inventory of didactic books that should be adopted by the school units scattered around the country. Then, we've concluded that the knowledge for teaching and the knowledge to teach arithmetic were instituted from the expertise of João Luderitz, 
coordinator of the Remodeling Service, and his team. Concerning the knowledge for teaching arithmetic, the intuitive method was the reference. Now, the knowledge to teach arithmetic was restructured based on the proposal of the Remodeling Service pushing away the initial assistentialist purpose focused only in literacy, thus giving it a more scientific status.

Keywords: Escola de Aprendizes Artifices de Santa Catharina. Arithmetic Teaching. Professional Education. Knowledge for teaching. Knowledge to teach.

\section{Resumen}

La Escola de Aprendizes Artifices de Santa Catharina fue una importante institución de enseñanza profesional y que ofrecía la enseñanza elemental gratuita. Con ello, el propósito de este artículo es de investigar saberes relacionados a los que haceres pedagógicos de la enseñanza de aritmética del curso primario de esta Escuela. Para ello, serán analizados los informes del Servicio de Remodelación de la Enseñanza Profesional Técnico de la década de 1920 y del libro Arithmetica Elementar Illustrada, 92a edición, de 1922, de Antônio Bandeira Trajano. El instrumento teóricos y metodológico utilizado para el análisis de los documentos fueron los saberes para enseñar y los saberes a enseñar desarrollados por el Equipo de Investigación en Historia Social de la Educación (ERHISE) a partir de sus estudios socio históricos vinculados a la Historia Cultural. Los informes del Servicio de Remodelación sugieren propuestas que resultan en cambios significativos en la enseñanza profesional como, por ejemplo, la adopción de una única estructura curricular y un inventario de libros didácticos que deberían ser adoptados por las unidades escolares repartidas por el país. De ese modo, concluimos que los saberes para enseñar y los saberes a enseñar aritmética fueron instituidos a partir de la experiencia de João Luderitz, coordinador del Servicio de Remodelación, y su equipo. En lo que se refiere a los saberes para enseñar aritmética, el método intuitivo fue la referencia. Los saberes a enseñar aritmética fueron reestructurados con base en la propuesta del Servicio de Remodelación alejándolos de su propósito inicial asistencialismo orientado sólo a la alfabetización, dando así un status más científico.

Palabras clave: Escola de Aprendizes Artífices de Santa Catharina. Enseñanza de aritmética. Enseñanza profesional. Saberes para enseñar. Saberes a enseñar. 


\section{Introdução}

\section{Considerações históricas}

As Escolas de Aprendizes Artífices (EAAs) foram criadas pelo Decreto $\mathrm{n}^{\circ} 7.566$ de 23 de setembro de 1909 e podem ser consideradas como marco inicial de uma política de governo para instituir o ensino profissionalizante, de ofícios, no Brasil, como aponta Soares (1982). Sancionada no governo de Nilo Peçanha, o documento cria, por intermédio do Ministério da Agricultura, Indústria e Comércio, dezenove Escolas de Aprendizes Artífices, que constituíram uma rede de ensino profissional primário e gratuito, e que foram instaladas em cada um dos estados da federação ${ }^{1}$, exceto no Distrito Federal e no Rio Grande do Sul ${ }^{2}$. Salvo o estado do Rio de Janeiro ${ }^{3}$, as EAAs localizavam-se na capital de cada estado. Essas escolas eram mantidas pelo Governo Federal e regulamentadas por meio de decreto federal.

A criação das escolas ocorre no período da Primeira República que, segundo Manfredi (2002), é um período em que o país ingressa em uma nova fase econômico-social, em decorrência dos processos de industrialização e urbanização. Ainda de acordo com a autora, é neste cenário de criação de novos empreendimentos industriais e surgimento de grandes centros urbanos que setores da economia passam a modernizar-se tecnologicamente, gerando uma demanda de qualificação profissional.

Em resposta aos desafios de ordem econômica e política, o presidente Nilo Peçanha cria as EAAs. De acordo com Cunha (2000), no

1 Amazonas, Pará, Maranhão, Piauí, Ceará, Rio Grande do Norte, Paraíba, Pernambuco, Alagoas, Sergipe, Bahia, Espirito Santo, Rio de Janeiro, São Paulo, Paraná, Santa Catarina, Minas Gerais, Goiás e Mato Grosso.

2 No Decreto no 7.566/1909 essas duas unidades federativas não foram contempladas com a instalação das EAAs, pois nesses estados já havia a existência de institutos voltados para o ensino profissional. No estado do Rio Grande do Sul existia o Instituto Técnico Profissional da Escola de Engenharia de Porto Alegre e no Distrito Federal o Instituto Profissional Masculino (CUNHA, 2000).

3 Exceto o estado do Rio do Janeiro, que tem sua Escola de Aprendizes Artífices implementada fora da capital, na cidade de Campos (CUNHA, 2000). 
preâmbulo do Decreto $n^{0} 7.566 / 1909$ encontramos as motivações para a criação dessas escolas e seu público alvo, que vão ao encontro desses desafios. Para o autor, o termo "formar cidadão úteis a nação", que encontramos no decreto federal, expressa a frágil situação do país quanto à formação de força de trabalho qualificada frente às exigências do processo de industrialização. Nessa situação, no Art. $2^{\circ}$ do Decreto n $7.566 / 1909$, as escolas tinham como propósito "[...] formar operários e contra-mestres, ministrando-se o ensino prático e os conhecimentos técnicos necessários aos menores que pretenderem aprender um ofício [...]" (BRASIL, 1909a, p. 1). Ainda apoiado no texto de preâmbulo do Decreto $n^{\circ} 7.566 / 1909$, é possível apontar outros motivos para a criação das escolas. De acordo com o texto, as escolas eram destinadas às "classes proletárias" ou os "filhos desfavorecidos da fortuna", que tinham tendência a viver em ociosidade, cenário descrito no documento como "escola do vício e do crime". Diante disto, segundo Cunha (2000), era atribuída às escolas uma pedagogia corretiva, pois, como publicado no decreto federal, as EAAs tinham como uma de suas finalidades fazer o aluno "adquirir hábitos de trabalho profícuo" e "indispensável preparo intelectual”.

Neste primeiro regulamento, Decreto n ${ }^{0} 7.566 / 1909$, as escolas estavam estruturadas em: curso primário noturno, obrigatório aos alunos que não soubessem ler, escrever e contar; curso de desenho, obrigatório aos alunos que "carecessem" desta disciplina e um número de até cinco "oficinas de trabalho manual ou mecânica que foram mais convenientes e necessárias no Estado em que funcionar a escola, consultadas, quanto possível, as especialidades das industrias locais" (BRASIL, 1909a). No entanto, Cunha (2000) afirma que as oficinas de muitas EAAs estavam voltadas para o artesanato de interesse local, com uma maioria absoluta oferecendo cursos de alfaiataria, sapataria e marcenaria, e outras poucas unidades com cursos de carpintaria, ferraria, funilaria, selaria, encadernação, entre outros. Conforme o autor, poucas eram as EAAs que tinham o emprego de oficinas voltadas para o setor manufatureiro ou industrial. A Escola de Aprendizes Artífices de São Paulo torna-se uma exceção, pois procurou adaptar suas oficinas às exigências fabris. Ela foi uma das poucas 
escolas que teve o ensino de ofícios de tornearia, mecânica e eletricidade; no entanto, manteve as oficinas de carpintaria e artes decorativas que estavam voltadas para artesanato.

No período de sua existência, as EAAs passaram por diversas reformulações. Após o decreto inicial, no 7.566/1909 (BRASIL, 1909a), outros decretos de âmbito federal vieram a reformular e estruturar as diretrizes do ensino profissionalizante nessas escolas. Entre as mudanças, os decretos federais posteriores impactaram principalmente no que tange à estrutura do curso primário e de desenho, bem como à estruturação das competências dos profissionais que atuariam nesta modalidade de ensino. A reforma mais significativa atribui-se ao documento de Consolidação dos Dispositivos Concernentes às Escolas de Aprendizes e Artífices, de 1926. Este documento unificou os currículos das escolas estabelecendo uma estrutura curricular única e que deveria ser adotada por todas as unidades. Esse documento é fruto do trabalho realizado pelo Serviço de Remodelação do Ensino Profissional Técnico ${ }^{4}$, sob responsabilidade do engenheiro João Luderitz, que tinha como finalidade "examinar o funcionamento das escolas e propor medidas que remodelassem o ensino profissional, tornando-o mais eficiente" (FONSECA, 1961, p. 187). Esta remodelação ocorreu de forma verticalizada, ou seja, em âmbito nacional e com impactos nas unidades estaduais espalhadas pelo País, incluindo a Escola de Aprendizes Artífices de Santa Catharina.

A Escola de Aprendizes Artífices de Santa Catharina (EAA-SC) foi criada quase um ano após a publicação do Decreto n ${ }^{\circ} 7566 / 1909$. Como as demais escolas EAAs espalhadas pelo território nacional, inicia suas atividades oferecendo para a comunidade um curso primário, um curso de desenho e cursos profissionais de tipografia, encadernação, carpintaria e mecânica (ALMEIDA, 2010). Sendo assim, EAA-SC passa a ser uma escola de nível elementar e, concomitantemente a outras instituições de ensino de mesmo nível, oferece ensino primário em Santa Catarina, mais especificamente no

4 Neste trabalho, nos referenciaremos ao Serviço de Remodelação do Ensino Profissional Técnico como Serviço de Remodelação ou utilizando a sigla SRP. 
município de Florianópolis, onde se encontravam suas instalações. A fala dos governadores em mensagens encaminhadas para o congresso representativo do estado ${ }^{5}$ e reportagens de jornais da época ratificam os excelentes trabalhos prestados pela EAA-SC para o ensino elementar de Santa Catarina. Apesar de a Escola possuir estreitas ligações com o sistema de ensino estadual, outros documentos, como, por exemplo, relatórios de gestão dos diretores das Escolas de Aprendizes Artífices, permitem verificar que as reformas promovidas pelo Serviço de Remodelação do Ensino Profissional Técnico (SRP), ocorridas em âmbito federal, incidiram sobre as atividades de ensino do curso primário da EAA-SC.

A propósito, a partir do movimento de reformulação do ensino profissional promovido pelo SRP é possível perceber uma tentativa de se estabelecer um conjunto de saberes que sejam próprios para o ensino profissional. A institucionalização desta reforma conduz para um processo de especialização, desenvolvendo uma expertise profissional. Esta dinâmica terá repercussão sobre o ensino de matemática, mais especificamente sobre o ensino de aritmética. Sendo assim, o propósito deste artigo é realizar uma análise sobre este processo de reformulação promovido pelo Serviço de Remodelação, buscando identificar e compreender os saberes que se emanam deste processo, destacando a Aritmética.

Como é possível notar, as Escolas de Aprendizes Artífices protagonizam um importante momento na história do ensino profissional no Brasil no período da República (CUNHA, 2000; FONSECA, 1961; SOARES, 1982). Em consonância com as referências indicadas, pode-se afirmar que as Escolas de Aprendizes Artífices se constituem como a primeira iniciativa

5 Mensagem do governador Vidal José de Oliveira Ramos ao Congresso Representativo do Estado, de 1912, na parte de Instrução pública, retrata a importância da Escola de Aprendizes Artífices para o ensino elementar do Estado: "A escola primaria e o curso de desenho do estabelecimento prestam excelentes serviços, dando instrucção elementar a todos os alunnos matriculados" (SANTA CATARINA, 1912, p. 51). Outras mensagens de governadores de Santa Catarina ao Congresso Representativo do Estado também retratam a importância desta instituição para o ensino elementar de Santa Catarina. Estas estão disponíveis em: <https://repositorio.ufsc.br/ handle/123456789/6908>. Acesso em: 16 dez. 2017. 
do governo federal em instituir uma rede ensino profissional. Por este motivo e os movimentos de reforma ocorridos nessas instituições, elas têm sido objeto de investigação de muitos artigos e trabalhos acadêmicos em nível de mestrado e doutorado, que buscam contar um pouco de sua história dentro de contextos locais, ou seja, a partir do contexto social, político e econômico de cada estado onde foram implementadas.

O ensino profissional em Santa Catarina também tem sido investigado por trabalhos acadêmicos em nível de mestrado e doutorado. Dentro, do programa de pós-graduação em Educação Científica e Tecnológica da UFSC encontra-se em andamento uma pesquisa de doutorado no campo da História da educação matemática e o ensino profissional. Esta pesquisa se debruça sobre ensino de desenho para o ensino industrial, buscando "compreender de que modo o ensino de desenho foi se fabricando enquanto um dispositivo técnico-industrial na metade do século XX, especificamente em Santa Catarina" (KUHN; FLORES, 2016, p. 342). Este artigo distancia-se desta proposta de pesquisa na medida em que estabelece um recorte temporal diferente, de 1909 a 1929, período do início do século XX, e tem seu foco sobre o ensino de aritmética. Por outro lado, este artigo se aproxima de outros trabalhos, como Almeida (2010), Cintra (2004) e Marques (2012), quando se propõe a escrever a história da Escola de Aprendizes Artífices. Contudo, diferencia-se destes quanto ao objeto. Almeida (2010), em seu livro, trata da história da Escola de Aprendizes Artífices de Santa Catarina, no qual, de uma forma geral, descreve as suas instalações, seu funcionamento e sua estrutura de ensino. Marques (2012), em sua dissertação, tem como objeto de pesquisa o currículo da Escola de Aprendizes Artífices, com foco sobre as disciplinas de português e desenho. Cintra (2004), em sua dissertação, estuda o curso profissional de alfaiataria da Escola de Aprendizes Artífices. Já este artigo se debruça sobre o ensino de aritmética, presente como conteúdo no programa de ensino do curso primário de 1909 até 1925 e, mais tarde, na forma de disciplina na grade curricular proposta em 1926.

Apoiados no referencial saberes para ensinar e saberes a ensinar, desenvolvido pela Equipe de Pesquisa em Histórica Social da Educação, da Suíça, 
apresentamos as primeiras análises de um conjunto de relatórios do Serviço de Remodelação do Ensino Profissional Técnico (1922-1929) e um livro didático, de 1922, com o intuito de identificar alguns deslocamentos ocorridos no que diz respeito ao ensino de aritmética de modo a apontar quais saberes para ensinar e saberes a ensinar aritmética estão presentes nessas instituições. Este ferramental teórico-metodológico vincula-se à História Cultural que tem como seu campo de investigação a cultura escolar, compreendida neste artigo pela concepção atribuída por Dominique Julia:

[...] um conjunto de normas (grifos dos autores) que definem conhecimentos a ensinar e condutas a inculcar, e um conjunto de práticas (grifo os autores) que permitem a transmissão desses conhecimentos e a incorporação desses comportamentos; normas e práticas coordenadas a finalidades que podem variar segundo as épocas (JULIA, 2001, p. 10).

Para Faria Filho et al. (2004), Julia em sua concepção de cultura escolar nos convida a interrogar as práticas cotidianas sobre o funcionamento interno da escola. Assim, em consonância com a noção de Julia (2001), interpretamos neste trabalho a cultura escolar como uma realidade educacional socialmente construída tendo como base um conjunto de normas e práticas que definirão os saberes para ensinar e os saberes a ensinar. Sendo assim, a partir da análise das prescrições encontradas nos decretos federais e nos relatórios ministeriais, que determinaram reformas verticalizadas, busca-se compreender a dinâmica do ensino de aritmética da Escola de Aprendizes Artífices de Santa Catharina.

Em relação ao uso do livro didático como fonte de pesquisa, Choppin afirma que os livros didáticos "representam para os historiadores uma fonte privilegiada, seja qual for o interesse relativos à educação, à cultura ou às mentalidades [...] (2002, p. 13). Para este autor, o livro didático faz parte de uma "realidade material", que carrega em si conteúdos educativos constituídos de saberes que são julgados importantes para se transmitir às novas gerações; também pertence a um universo cultural, funcionando como um vetor de aculturação de valores, e é um instrumento pedagógico, 
posto que propõe métodos e técnicas de aprendizagem. Para Valente (2008), os livros didáticos submetidos aos questionamentos da pesquisa são fontes que revelam potenciais testemunhos sobre conteúdos escolares, metodologias, didáticas e, algumas vezes, orientações pedagógicas. A partir deles é possível captar os saberes para ensinar e saberes a ensinar aritmética que circularam pela Escola de Aprendizes Artífices de Santa Catarina.

\section{Saberes para ensinar e Saberes a ensinar como um instrumento para análise de documentos prescritivos de ensino}

A Equipe de Pesquisa em História Social da Educação (ERHISE ${ }^{6}$ ) tem se debruçado sobre as pesquisas sócio-históricas acerca da formação de professores e o ensino. As pesquisas do grupo apontam que os saberes fazem parte da engrenagem das instituições de ensino. Assim, segundo Hofstetter e Schneuwly (2017), os saberes ${ }^{7}$ vão se manifestar na forma de objeto e/ou de instrumento de ensino para os profissionais da docência. $\mathrm{O}$ foco de reflexão deste referencial recai sobre os saberes formalizados que estão associados aos saberes objetivados, que segundo Barbier ${ }^{8}$ (1996, p. 9 apud HOFSTETTER; SCHNEUWLY, 2017, p. 131) "são um conjunto de enunciados que possuem alguma valorização social sancionada por uma atividade de transmissão-comunicação". Em outras palavras, são saberes formalizados que se encontram materializados de alguma forma nos livros, documentos normativos de ensino, planos de aula, cadernos escolares, etc. Na visão desses autores, esses materiais fazem parte do cotidiano

6 ERHISE - Equipe de recherche en histoire sociale de l'éducation. Para maiores detalhes ver em: <https:// www.unige.ch/fapse/recherche/ssed/culture-organisation/erhise/>. Acesso em: 18 jan. 2018.

7 Destaca-se que os saberes aqui tratados se diferem daqueles mobilizados a partir da ação do docente e têm como fonte de estudo as experiências e vivências do professor. Ainda que os saberes aqui tratados estejam integrados à ação docente, o foco de reflexão deste referencial não recai sobre o sujeito, tal como acontece nos estudos e pesquisas que priorizam a análise da ação docente a partir do sujeito (professor).

8 BARBIER, J. Savoirs théoriques et savoirs d'áction. Paris: PUF, 1996. 
e dos afazeres pedagógicos e encontram-se presentes nas atividades de transmissão-comunicação feitas pelos docentes. Assim, é possível definir dois tipos constitutivos de saberes referidos à profissão docente: "os saberes a ensinar que são objetos do seu trabalho; e os saberes para ensinar, em outros termos os saberes que são as ferramentas do seu trabalho" (HOFSTETTER; SCHNEUWLY, 2017, p. 131).

Os saberes a ensinar constituem o objeto de trabalho do professor e estão associados aos saberes que devem ser ensinados ao aluno. Esses saberes estão diretamente ligados à instituição de ensino, que de alguma forma define o que se deve ou não ensinar. Manifestam-se principalmente em planos de ensino ou programas/currículos, em livros didáticos do aluno e do professor, em documentos que fornecem prescrições para o ensino e outros tipos documentos que de alguma forma venham dar alguma orientação quanto ao que se deve ensinar. Para Hofstetter e Schneuwly:

a escolha dos saberes e a sua transformação em saberes a ensinar é resultado de processos complexos que transformam fundamentalmente os saberes a fim de torná-los ensináveis. Esse processo pode até conduzir à criação de saberes próprios às instituições educativas, necessárias a elas para assumirem as suas funções (2017, p. 133).

Nesta proposta, apoiados na estrutura curricular estabelecida pelo documento de Consolidação dos Dispositivos Concernentes às Escolas de Aprendizes e Artífices e em um livro didático procuramos identificar quais seriam os "objetos" de trabalho do professor do curso primário quanto ao ensino de aritmética. Para além dos conteúdos prescritos, busca-se olhar para as finalidades e propósitos destes saberes, para se compreender a escolha e a instituição destes saberes a ensinar.

Por outro lado, os saberes para ensinar são saberes que se relacionam com os objetos do trabalho de ensino, as práticas de ensino e as instituições que definem a atividade profissional docente. Quanto aos objetos do trabalho de ensino, os saberes para ensinar podem estar associados aos saberes a ensinar e aos alunos (seus conhecimentos, seus desenvolvimentos, as maneiras de aprender, etc.). Já quanto as práticas de ensino, os 
saberes para ensinar estão associados aos métodos, procedimentos, dispositivos, escolhas dos saberes a ensinar, modalidade de organização e de gestão. Sobre as instituições, os saberes para ensinar estão associados aos planos de aula, às instruções e prescrições de ensino, às finalidades das instituições de ensino, às estruturas administrativas e políticas que regulamentam e normatizam o sistema de ensino, etc. Isto posto, a partir do trabalho de Queluz (2000) e dos relatórios ministeriais, procura-se caracterizar o ensino de matemática das EAAs, com foco sobre o ensino de aritmética, procurando capturar métodos utilizados, conhecimentos priorizados, orientações pedagógicas, etc.

Ambos os saberes poderão ter como referência para a sua produção uma comunidade científica, um grupo de profissionais ou ainda os experts. Neste contexto, a expertise profissional é entendida aqui como:

Uma instância, em princípio reconhecida como legítima, atribuída a um ou vários especialistas - supostamente distinguidos pelos seus conhecimentos, atitudes, experiências - , a fim de examinar uma situação, de avaliar um fenômeno, de constatar fatos. Esta expertise é solicitada pelas autoridades do ensino tendo em vista a necessidade de tomar uma decisão. A solicitação de expertise, veremos, participa decisivamente da produção de novos saberes no campo pedagógico (HOFSTETTER; SCHNEUWLY; FREYMOND, 2017, p. 57).

Posto isso, procura-se também analisar o papel das pessoas (os experts) que participaram do Serviço de Remodelação, principalmente no que tange a escolha e sistematização dos saberes para ensinar e saberes a ensinar aritmética nas EAAs. 


\section{A Escola de Aprendizes Artífices de Santa Catharina e seus saberes para e a ensinar Aritmética a partir dos relatórios do Serviço de Remodelação do Ensino Profissional e Técnico}

Em 1927, ano seguinte à promulgação do documento de Consolidação Concernente à Escola de Aprendizes Artífices, ocorre no estado de Santa Catarina a primeira Conferência do Ensino Primário. Neste evento, o então diretor da Escola de Aprendizes e Artífices de Santa Catharina (EAA-SC), o Sr. João Candido da Silva Muricy, realiza um discurso para demais autoridades presentes no evento:

Temos um programma novo, uma remodelação completa dos nossos velhos systemas de ensino: - A Commissão de Remodelação do Ensino Profissional Technico, chefiada pelo illustre Engenheiro dr. João Luderitz, no Ministerio da Agricultura, por esse programma, tudo modificou, tudo methodisou, de modo que houve como que um extremecimento entre nossos aprendizes; uma extranha apreciação da transformação, que se pode chamar, radical (KONDER, 1927, p.48).

Em seu discurso, é possível perceber mudanças promovidas pelo Serviço de Remodelação no ensino profissional nas EAA-SC, que indicam indícios de modificações sobre os saberes do ensino profissional. Ao relatar modificações nos programas, compreendemos que houve possíveis mudanças que atingem o objeto de trabalho dos professores desta escola, ou seja, sobre os saberes a ensinar. Também, quando descreve que "tudo methodisou" entendemos que possam ter ocorrido alterações no âmbito dos saberes para ensinar. O próprio diretor João Muricy reconhece os impactos das mudanças propostas pelo Serviço de Remodelação quando relata a "transformação" como "radical". Desta forma, nota-se que a reforma promovida pelo Serviço de Remodelação no ensino profissional foi um processo vertical. Com isso, geraram-se algumas dificuldades e "extranha apreciação", na fala do diretor. É a partir deste discurso que surge o interesse em realizar uma análise nos relatórios do Serviço de Remodelação, 
com intuito de compreender quais mudanças ocorreram sobre os saberes para ensinar e os saberes a ensinar aritmética.

\section{Relatórios do Serviço de Remodelação (1922 - 1929) e as referências para os saberes para ensinar e saberes a ensinar aritmética}

Os relatórios do Serviço de Remodelação do Ensino Profissional que podem ser encontrados nos relatórios anuais emitidos pelo Ministério da Agricultura, Indústria e Comércio permitem compreender melhor o funcionamento e as finalidades deste serviço. Nesses documentos encontramos as descrições de suas atividades e um conjunto de informações quanto aos serviços realizados. Por este motivo, os relatórios se configuram como valiosas fontes de pesquisa, pois a partir delas podemos compreender a dinâmica oficial do Serviço de Remodelação, o que nos permite identificar elementos do movimento de transformação sobre os saberes para ensinar e saberes a ensinar. Então, para captar esses elementos foram analisados os relatórios ministeriais entre 1922 e 1929.

É no relatório do ministro João Gonçalves Pereira Lima, de 1918, que o governo federal reconhece que há a necessidade de melhorar o funcionamento do ensino profissional das EAAs, e com isso cria-se o Decreto $\mathrm{n}^{\mathrm{o}}$ $13.064^{9}$ de junho de 1918 (BRASIL, 1918b). Mas, é somente em 1920, sob a forma de uma comissão, que se cria o Serviço de Remodelação do Ensino Profissional Técnico, que tinha a finalidade de tornar o ensino profissional mais eficiente examinando o funcionamento das escolas e propondo medidas que os remodelassem (BRASIL, 1920). Portanto, os relatórios de 1918 e 1920 apontam para a reivindicação de novas expertises, na medida em que essa ação demandaria do conhecimento propício de especialistas para avaliar o ensino profissional das Escolas de Aprendizes Artífices espalhadas pelo País e ainda propor mudanças. Para Hofstetter, Schneuwly e Freymond (2017) “a solicitação de expertise participa poderosamente da produção

9 BRASIL, 1918a. 
de novos saberes no campo pedagógico" (HOFSTETTER; SCHNEUWLY; FREYMOND, 2017, p. 57).

O engenheiro João Luderitz foi nomeado para realizar uma avaliação do ensino profissional das Escolas de Aprendizes Artífices. Assumiu em 1908 como Diretor do Instituto Técnico-Profissional de Porto Alegre, "mais tarde denominado Instituto de Parobé" (CUNHA, 2000, p. 67). No ano seguinte, em 1909, Luderitz inicia uma viagem pela Europa e Estados Unidos com alguns propósitos, dentre eles "encontrar novos modelos de ensino profissional que pudessem ser aplicados no Brasil" (QUELUZ, 2000, p. 108). Na ocasião, ele estava em busca de elementos que pudessem constituir uma proposta de reformulação dos processos educativos do ensino profissional e que correspondessem às demandas político-filosóficas de seus superiores (QUELUZ, 2000).

Nesta viagem, Luderiz visitou instituições de ensino profissional ${ }^{10}$, onde ficou fascinado pelos museus técnicos que tanto facilitariam o ensino de desenho. A partir desta inspiração, ele tratou de instalar um museu no Instituto Técnico-Profissional de Porto Alegre. Contudo, sua maior fonte de inspiração foi o Instituto de Berna, da Suíça, de onde ele extrairia elementos para compor sua proposta de ensino profissional, apoiado no ensino de Desenho Industrial e Tecnológico e na prática de oficina, agregadas à industrialização da produção e a comercialização sistemática. Contudo, sua maior crítica a este instituto foi quanto ao ensino de Matemática, que faria ele ter como fonte de inspiração os modelos de ensino técnico secundário norte-americanos. Para ele, a matemática forneceria elementos para a formação técnico-científica e para os cursos de Desenho (ornamental, industrial e tecnológico) (QUELUZ, 2000). Por este motivo, os conteúdos voltados para o ensino de matemática deveriam ser fortalecidos. Esta concepção motivou João sugerir uma divisão no ensino de matemática, onde havia um grupo de disciplinas voltado

10 Conservatório de Artes e Ofícios, de Paris, e Koeninsgliche Vereinigte Maschinenbauschulen, da Alemanha (QUELUZ, 2000). 
para ensino elementar, de formação geral, e outro para o ensino complementar, para a formação técnico-científica.

Conforme Queluz (2000), as viagens realizadas por Luderitz foram essenciais para que ele criasse uma concepção de ensino profissional que seria posteriormente implementada, primeiramente, no Instituto Profissional Técnico de Porto Alegre e, por último, nas Escolas de Aprendizes Artífices. Deve-se ressaltar que as reformas aplicadas por João fizeram com que o Instituto de Parobé ganhasse reconhecimento em âmbito nacional quanto a seu ensino profissional. Este foi um dos motivos de escolha do então ministro Ildefonso Simões Lopes por João Luderitz para liderar a reforma do ensino profissional nas Escolas de Aprendizes Artífices. Também, havia uma afinidade do então ministro pelos princípios educacionais aplicados no Instituto Parobé.

A partir dos trabalhos realizados pelo Serviço de Remodelação, cria-se, em 1923, uma proposta de regulamento do Ensino Profissional (NAGLE, 1976, p. 166). Esta proposta vai ser a base para a construção do documento de Consolidação dos Dispositivos Concernentes às Escolas de Aprendizes Artífices, promulgada pela portaria de 13 de novembro de 1926, que trará em seu conteúdo complementos para o regulamento em vigor, ou seja, o Decreto $n^{0}$ 13.064. Enquanto no decreto federal em vigor as atribuições em relação aos assuntos do ensino eram evasivas, o documento de Consolidação tratará deste assunto de forma mais acurada. Além disto, este documento trará em seu teor artigos que regulamentam o ensino profissional oferecido pelas EAAs. Uma das propostas do documento de Consolidação é de que o ensino primário seja dividido em duas etapas: elementar e complementar, o que acaba estendendo a formação do aluno de 4 anos para 6 anos. A inserção do nível complementar de ensino é uma tentativa de Luderitz de implementar o ensino secundário nas EAAs (QUELUZ, 2000), ainda que esta ideia não fosse ser adotada em sua totalidade pelo governo. Aqui podemos notar uma necessidade de se estabelecer uma nova conotação para o ensino profissional, afastando-o de uma concepção mais assistencialista e trazendo para ele uma concepção mais científica. Por este motivo, segundo Queluz (2000), para João Luderitz o ensino elementar 
assumia um caráter mais formativo, voltado para uma cultura geral, enquanto o complementar estava voltado mais para uma formação científica. De fato, este movimento conduz o ensino profissional para novas referências de saberes para ensinar e saberes a ensinar aritmética.

Quanto aos aspectos de saberes a ensinar, ou seja, sobre o "objeto de trabalho" do professor, temos como uma das primeiras alterações a criação das disciplinas voltadas ao ensino de matemática:

Os cursos primarios e de desenho abrangerão as seguintes disciplinas: portuguez, arithmetica, geometria pratica, lições de cousas, desenho e trabalhos manuaes, calligraphia, gymnastica e canto coral, chorographia e historia do Brasil, instrucção moral e civica, elementos de álgebra, noções de trigonometria, rudimentos de physica e chimica, desenho industrial e tecnologia de cada officio (BRASIL, 1926, Parágrafo único I).

No Decreto $n^{0} 7.763$, de 23 de dezembro de 1909, que é uma consolidação dos dois decretos federais antecedentes ${ }^{11}$, nas Instruções ${ }^{12}$ a que se refere o decreto federal, em seu art. 3 , inciso 2 , faz-se a seguinte referência ao ensino de matemática no curso primário:

Inciso $2^{\circ} \mathrm{O}$ Curso primario, que funcionará da 5 horas da tarde ás 8 da noite, terá por fim o ensino de leitura e de escripta, o de arithmetica até regra de tres, noções de geographia do Brazil e o de grammatica elementar da lingua nacional (BRASIL, 1909c).

A descrição "arithmetica até regra de três" faz referência da aritmética como uma matéria escolar ${ }^{13}$ do curso primário, visto que os conteúdos prescritos tinham como finalidade inicial a alfabetização dos alunos que ingressavam nas EAAs, isto é, como componente integrante da tríade ler-escrever-contar. No Decreto ${ }^{\circ} 7.763$ (BRASIL, 1909c) temos que o ensino

11 Os Decretos no 7.566 (BRASIL, 1909a) e no 7.649 (BRASIL, 1909b).

12 Este documento é um anexo do Decreto no 7.763 de 23 de dezembro de 1909 (BRASIL, 1909c).

13 "[...] caberia caracterizar uma matéria escolar como um conjunto de conteúdos interligados ao processo de ensino que envolve a tríade ler-escrever-contar (VALENTE, 2015, p.358). 
de aritmética está organizado na forma de um conjunto de conteúdos e não em disciplinas. O programa do curso primário, de 1916, presente no relatório de gestão do diretor Heitor Blum ${ }^{14}$ ratifica esta conclusão.

Com as mudanças instituídas por Luderitz em 1926 parece haver uma mudança de status da aritmética de matéria escolar para disciplina. Identifica-se esse movimento que ocorre quando esse conjunto de conteúdos passa a adquirir um caráter disciplinador. De acordo com Chervel (1990), as concepções em torno da constituição de disciplinas escolares estão para além de uma visão de que elas são uma mera vulgarização de ciências, ainda que elas possuam uma maior proximidade com as disciplinas universitárias do que a matéria escolar. Elas estão no centro do ensino; sendo assim, a partir delas é possível apreender fenômenos de aculturação dos conteúdos que ela determina, ou ainda, os saberes a ensinar, e as finalidades e objetivos de que ela se ocupa, ou seja, os saberes para ensinar. Em outras palavras, olhar para as motivações de Luderitz para propor a aritmética como uma disciplina escolar no documento de Consolidação nos permite capturar as referências de saberes para ensinar e saberes a ensinar aritmética.

A falta de uniformidade nos programa de ensino, tanto do curso primário quanto dos cursos profissionais, estava comprometendo a unidade das escolas. Então, em 1926, a partir do documento de Consolidação, estabeleceu-se uma estrutura curricular que padronizou o curso primário das EAAs e que deveria ser adotado pelas diferentes escolas (BRASIL, 1926). Este currículo estava prescrito no documento de Consolidação:

14 BRASIL, 1917. 
Quadro 1 - Estrutura curricular do ensino profissional primário apresentado pelo Serviço de Remodelação do Ensino Profissional Technico

\begin{tabular}{|c|c|}
\hline \multicolumn{2}{|r|}{ Grade Curricular do Ensino Elementar } \\
\hline 10 anno & $\begin{array}{l}\text { Leitura e escripta; Calligrapphia; CONTAS; Lição de cousas; Desenho e trabalhos } \\
\text { manuaes; Gymnastica e canto }\end{array}$ \\
\hline 2o anno & $\begin{array}{l}\text { Leitura e escripta; CONTAS; Elementos de geometria; Geographia e historia } \\
\text { pratica; Calligrapphia; Instrucção moral e civica; Lição de cousas; Desenho e } \\
\text { trabalhos manuaes; Gymnastica e canto }\end{array}$ \\
\hline 3o anno & $\begin{array}{l}\text { Portuguez; ARITHMETICA; Geometria; Geographia e historia pratica; Lição } \\
\text { de cousas; Calligrapphia; Instrucção moral e civica; Desenho ornamental e de } \\
\text { escala; Aprendizagem nas officinas }\end{array}$ \\
\hline 4ㅇ anno & $\begin{array}{l}\text { Portuguez; ARITHMETICA; Geometria; Rudimentos de physica; Instrucção moral } \\
\text { e civica; Desenho ornamental e de escala; Desenho industrial e techonologia; } \\
\text { Aprendizagem nas officinas. }\end{array}$ \\
\hline \multicolumn{2}{|r|}{ Grade Curricular do Ensino Complementar } \\
\hline 10 anno & $\begin{array}{l}\text { Escripturação de officinaas e correspondência; Geometria aplicada e noções de } \\
\text { álgebra e de trigonometria; Physica experimental e noções de chimica; Noções } \\
\text { de historia natural; Desenho industrial e tecnologia } \\
\text { Aprendizagem nas officinas. }\end{array}$ \\
\hline 2ㅇ anno & $\begin{array}{l}\text { Correspondencia e escripturação de officinas; Algebra e trigonometria } \\
\text { elementares; Noções de physica e chimica aplicada; Noções de mecânica; } \\
\text { Historia natural e elementar; Desenho industrial e tecnologia } \\
\text { Aprendizagem }\end{array}$ \\
\hline
\end{tabular}

Fonte: Relatório do Serviço de Remodelação do Ensino Profissional Thecnico, 1926 (BRASIL, 1926).

Nesta estrutura curricular pode-se notar a presença da "disciplina" Contas, que irá compor a grade curricular de disciplinas voltadas para a Matemática, ainda que ela não esteja descrita no documento como uma disciplina. Esta nomenclatura "Contas" é algo herdado da reforma realizada por Luderitz no Instituto Técnico-profissional de Porto Alegre. Neste estabelecimento de ensino profissional:

[...] a tendência de intensificar o caráter formativo do curso elementar aparece na mudança das denominações das disciplinas adequando-se àquelas vigentes no ensino primário em geral: Aritmética 
se transformaria em Contas, Português seria Escrita e Caligrafia (QUELUZ, 2000, p. 124) ${ }^{15}$.

Ainda, de acordo com o mesmo autor, o ensino de aritmética possuía duas naturezas: uma estritamente formativa, com finalidade de fortalecer os conhecimentos básicos e as notações matemáticas, e outra prática, com a finalidade de fornecer elementos para aplicações em problemas do cotidiano orçamentário das oficinas. Então, aqui temos uma referência para escolha dos saberes a ensinar. Neste caso, entendemos que a disciplina de "Contas" estaria ligada à primeira finalidade, enquanto a disciplina de "Arithmética" estaria voltada para as questões práticas. Todavia, ambas as disciplinas fazem parte do ensino elementar, ou seja, de um processo formativo geral. A divisão gerada quanto ao ensino de aritmética também exige novas referências para os saberes para ensinar, uma vez que esses saberes estão associados às escolhas dos saberes a ensinar, à maneira de aprender, etc. A seguir apresenta-se uma análise do livro didático que aponta os saberes a ensinar e os saberes para ensinar associados ao ensino de aritmética.

\section{Arithmetica Elementar Illustrada e os saberes para e a ensinar aritmética da Escola de Aprendizes Artífices de Santa Catharina}

O relatório ministerial de 1924 descreve a falta de uniformidade e generalização de compêndios para o ensino elementar (BRASIL, 1924). Com isso, foi nomeada, por meio de uma resolução, uma comissão composta de profissionais no assunto de ensino para deliberar sobre a adoção de livros escolares. Nota-se aqui a solicitação da expertise de um grupo de especialistas quanto à escolha dos livros que seriam amplamente

15 A notação matemática, por sua vez, aparece bem contemplada no programa de ensino, aproximando-se daquela desenvolvida no Instituto Parobé, com a transmissão das noções básicas de Aritmética, Álgebra, Geometria, Trigonometria e Geometria Aplicada (QUELUZ, 2000, p.172). 
adotados pelas EAAs. Então, o Serviço de Remodelação solicitou a remessa de exemplares de compêndios em uso nas 19 escolas nos diversos estados brasileiros, que seriam usados pela comissão com a finalidade de emitir um juízo sobre a verdadeira situação do ensino ministrado nas escolas e deliberar sobre a adoção dos compêndios mais adequados. Para compor esta comissão foram nomeados Heitor Lyra da Silva (relator), Afrânio Peixoto e Victor Vianna.

Considerados como intelectuais em sua época, Heitor, Afrânio e Victor participavam ativamente de movimentos educacionais que buscavam melhorias do ensino brasileiro. Heitor Lyra da Silva foi um dos fundadores da Associação Brasileira de Educação (ABE), em 1924 ${ }^{16}$. Também, é autor do livro Geometria, que foi adquirido pelo Serviço de Remodelação, em 1925, e distribuído para as EAAs (BRASIL, 1925). Victor Vianna era um escritor do Jornal do Commercio, de São Paulo, e produzia críticas pedagógicas e literárias (MATHIESON, 2017). Representou o Governo Federal na Conferência Interestadual de Ensino Primário, de $1921^{17}$. Afrânio Peixoto dedicou-se ao aperfeiçoamento da formação de educadores, em especial dos professores primários. Foi diretor da Escola Normal do Rio de Janeiro, em 1915, e assumiu a cadeira de História da Educação no Instituto de Educação do Rio de Janeiro, em 1932. Também foi autor de livros didáticos e de Pedagogia ${ }^{18}$. Portanto, a escolha desses nomes para compor a comissão não foi aleatória; teve como base a produtiva atuação deles no contexto educacional brasileiro.

Em 1925, a comissão envia para as escolas um relatório onde fazia indicações dos livros que deveriam merecer preferência. O governo então compra alguns exemplares dos livros indicados e os distribui para as escolas. Para o ensino de aritmética, a indicação foi o livro Arithmetica

16 Informações extraídas do site da Associação Brasileira de Educação. Disponível em: <http://www. abe1924.org.br/quem-somos/galeria-dos-presidentes/106-heitor-lyra>. Acesso em: $28 \mathrm{dez} .2017$.

17 Informação extraída do Annaes da Conferência Interestadual de Ensino Primario. Disponível em: <http://seer.ufrgs.br/asphe/article/viewFile/30166/pdf>. Acesso em: 28 dez. 2017.

18 Informações extraídas do site da Associação Brasileira de Educação. Disponível em: <http://www. abe1924.org.br/quem-somos/galeria-dos-presidentes/95-afranio-peixoto>. Acesso em: 28 dez. 2017. 
Pratica do autor Ruy de Lima e Silva. No entanto, esta mesma comissão faz uma ressalva que concede às escolas autonomia para que elas mesmas pudessem realizar editais de concurso para a adoção de livros:

Deliberando, assim, sobre a conveniencia da adopção dos compendios mais adequados, sob o ponto de vista pedagógico e econômico, a referida commissão propoz tambem a publicação de editaes, indicando, para cada materia do programma das escolas, quaes os requisitos a serem preenchidos pelas obras que pretendem adopção definitiva. Haverá, assim, segundo a commissão, verdadeiros concursos, a que poderão apresentar-se não só as obras já editadas, mas tambem trabalhos inéditos, porventura superiores a alguns daqueles (BRASIL, 1925).

Em concordância com as orientações da comissão, em um edital $^{19}$ do ano de 1928, publicado no Jornal República, de Florianópolis, a EAA-SC estava licitando "livros para aulas"20. Seriam comprados um exemplar de cada livro: Arithmetica Pratica e Formulario de Ruy de Lima e Silva; Arithmetica de Olavo Freire (curso elementar e médio) e Arithmetica elementar de Antônio Bandeira Trajano.

A partir de uma breve análise do livro Arithmetica Elementar Illustrada, 92ª edição, de 1922, de Antônio Bandeira Trajano, deseja-se capturar os saberes para ensinar e saberes a ensinar aritmética associados a esta obra. A partir da análise desta obra pode-se ter noção de quais conteúdos aritméticos devem ser priorizados e quais métodos de ensino estão associados. Dado que este material foi adotado pela EAA-SC e recomendado pela comissão avaliadora dos compêndios do Serviço de Remodelação, é possível considerá-lo como um veículo de circulação de conhecimentos e métodos com reconhecido valor para o ensino profissional. Logo, este

19 MURICY, J. C. S. Ministerio da Agricultura, Industria e Commercio, Escola de Aprendizes Artifices de Santa Catharina. República, 1928, Ano II, n. 421, 25 fev., p.4, SC. Disponível em: <http://memoria. bn.br/DocReader/DocReader.aspx?bib=711497x\&pesq=Escola\%20de\%20Aprendizes\%20e\%20 Art\%C3\%ADfices\&pasta=ano\%201928\edicao\%2000421>. Acesso em: 16 dez. 2017.

${ }^{20}$ Era assim que estava descrito no edital. 
compêndio, e os demais recomendados, fazem parte de um movimento de objetivação destes saberes.

A escolha desta obra para a análise deve-se pelo fácil acesso ao material inventariado. Uma cópia digitalizada deste livro encontra-se disponível no Repositório de Conteúdo Digital (RCD) da UFSC ${ }^{21}$, um espaço virtual no qual uma comunidade intitulada História da Educação Matemática aloca documentos digitalizados de diversas naturezas, como manuais pedagógicos, livros didáticos, revistas pedagógicas, legislações escolares e etc. Costa e Valente (2015) descrevem o RCD como um banco de dados composto de documentos que poderão ser mobilizados, tornando-se fontes em pesquisas no âmbito da história da educação matemática.

A obra analisada foi aprovada pelo Conselho Superior de Instrução da Capital Federal para o uso nas escolas primárias. Nas EAAs seriam usadas no ensino elementar. Nas páginas iniciais, consta a informação acerca do prêmio outorgado pelo Jury da Exposição do Rio de Janeiro e da adoção da obra pela Instrução Pública em vários Estados do Brasil. As duas chancelas lhe atribuem um respeitado valor social. Esta valorização faz com que este livro seja adotado por vários Estados brasileiros, potencializando sua circulação no âmbito nacional. Sendo assim, este livro atua sobre os saberes a ensinar e saberes para ensinar aritmética, propagando um conjunto devidamente ordenado de conteúdos que devem ser considerados e a maneira de abordá-los.

Muitos são os trabalhos realizados pelo grupo GHEMAT que tratam das obras de Antônio Trajano. A pesquisa realizada por Oliveira (2013), intitulada Antônio Bandeira Trajano e o método intuitivo para o ensino de Aritmética, aponta a presença do método intuitivo, proposto por

21 A alimentação da comunidade História da Educação Matemática é coordenada pelo prof. Dr. David Antonio da Costa. Esta documentação encontra-se disponível no endereço: <https://repositorio. ufsc.br/handle/123456789/1769>. Acesso em: 16 dez. 2017. 
Pestalozzi ${ }^{22}$, nas obras ${ }^{23}$ de Trajano. Então, percebe-se a presença do método intuitivo para o ensino de aritmética pela EAA-SC para o ensino elementar, visto que a obra de Olavo Freire - outra obra recomendada pela Comissão, voltada para o ensino de aritmética - também tinha a presença do método intuitivo, como descreve Trindade (2016). Outras EAAs também adotavam o método intuitivo como metodologia para o ensino. Pereira (2012) descreve que a Escola de Aprendizes Artífices de Minas Gerais (EAA-MG) procurava adotar o método intuitivo para o seu curso primário, estando em conformidade com o método que também era adotado pelos grupos escolares daquele estado. Ao que tudo indica, do mesmo modo que ocorreu com a Escola de Minas Gerais, em Santa Catarina o método de ensino aplicado ao ensino elementar da Escola de Aprendizes procurou ficar em consonância com os métodos de ensino dos Grupos Escolares do Estado. Em uma reportagem do Jornal República ${ }^{24}$, de 1921, temos que técnicos que compunham a equipe de remodelação de João Luderitz realizaram visitas em Grupos Escolares e examinaram seus programas de ensino. De um modo geral, o método intuitivo era bem aceito pelo Serviço de Remodelação como método a ser aplicado nas Escolas de Aprendizes Artífices. No relatório de 1925, há relatos de compra de outros livros didáticos e materiais que seriam usados no ensino intuitivo do curso elementar:

Ao mesmo tempo comprou-se, de accôrdo com a referida relação grande quantidade de quadros, hymnarios, mapas, cadernos e ouros livros didacticos para o ensino intuitivo das disciplinas do curso elementar, os quaes foram distribuídos pelas Escolas de Manáus, São Luiz, Natal,

22 Johann Heinrich Pestalozzi foi um educador suíço que desenvolveu uma educação ancorada em uma metodologia que ele denominou de método intuitivo. Este método tinha na intuição e na observação um fundamento para a construção do conhecimento (OLIVEIRA, 2013, p. 53).

${ }^{23}$ Oliveira (2013) descreve as obras de Trajano como uma trilogia Arithmetica composta em Arithmetica Progressiva, Arithmetica Elementar Illustrada e Arithmetica Primaria. Essas obras tinham o propósito de modernizar o ensino de Aritmética.

24 Reportagem sobre a visita da equipe de remodelação para examinar os programas de ensino dos Grupos Escolares de Santa Catarina disponível em: <http://memoria.bn.br/DocReader/docreader. aspx?bib=711497x\&pasta=ano\%20192\&pesq=Antonio\%20Hilario >. Acesso em: 16 dez 2017. 
Parahyba, Recife, Aracajú, Bahia, Bello Horizonte, Cuyabá, Campos, São Paulo, Curytiba e Florianopolis (BRASIL, 1925).

De acordo com Queluz (1998), ainda que o método intuitivo, pautado em um ensino teórico e prático, tenha sido "a visão educacional característica no início da República, estando presente nas primeiras reformas educacionais" (QUELUZ, 1998, p. 100), as ideias reformistas do Serviço de Remodelação reivindicavam a presença de saberes para ensinar que aproximassem os conhecimentos teóricos e práticos aos trabalhos de oficinas, de modo a contribuir com elementos - saberes para ensinar e saberes a ensinar - para uma sólida formação profissional:

Não é, tão pouco, aconselhável deixar de correr parallelamente, sem nexo de uma com a outra, a aprendizagem manual dos officios e a educação humanística: deve haver a mais intima ligação entre as aulas theorico-praticas e os trabalhos de officina, para que com poucos padrões educativos de obras a serem executadas pelo alunnos, se lhes possa dar, além de elementos de tecnologia e desenho industrial, as noções imprescindíveis de mathematica elementar e rudimentos de sciencias naturaes aplicadas ás profissões, de vernáculo aplicado á redacção da correspondência e contabilidade das industrias, tudo diretamente ilustrado com casos concretos dos problemas, que ocorrem na execução dos trabalhos de aprendisagem[...] (BRASIL, 1920).

Não cabe neste artigo identificar quais saberes para ensinar ligam os conhecimentos teórico-práticos às oficinas, visto que o foco está no ensino de aritmética. Quanto a isto, a obra Arithmetica Elementar Illustrada de Trajano contém os saberes a ensinar que atendem aos anseios relatados. Por exemplo, a partir do índice de sua obra verifica-se a presença dos conteúdos de Porcentagem, Juros, Desconto e Cambio, que desempenham um papel significativo no desenvolvimento das noções de "contabilidade das industrias", ainda que conteúdo, exemplos e problemas expostos no livro não sejam direcionados para o ramo industrial. Quanto aos saberes para ensinar encontra-se indicado no livro analisado o uso do método analítico: 
Cada um sabe, e muitos de experiência própria, o desgosto e o desanimo que o estudo da regra de três, de juros, etc, causa aos principiantes, sobrecarregando-lhes a memória, e o prazer que ao contrário, lhe dá o methodo analytico, chamado de redução a unidade, pela facilidade com que o aprendem e aplicam (TRAJANO, 1922, p. 4).

Entende-se que a obra de Trajano serviu como uma das importantes referências para "Contas" e "Arithmetica", na EAA-SC, contribuindo para a definição dos saberes a ensinar aritmética e a difusão do método intuitivo que se constitui como saberes para ensinar aritmética. Portanto, os conteúdos desta obra contêm, ainda que em parte, os saberes objetivados que deveriam ser apropriados pelo professor do ensino elementar da EAA-SC.

\section{Considerações finais}

A Escola de Aprendizes Artífices de Santa Catharina foi uma importante instituição de ensino profissional e, também, de ensino elementar. A importância desta instituição de ensino pode ser observada tanto nas falas de governadores presentes nas mensagens encaminhadas ao congresso representativo do estado quanto nas que foram referendadas nos jornais da época.

O relatório do Serviço de Remodelação do Ensino Profissional Técnico aponta para a constituição de novas referências para os saberes para ensinar e os saberes a ensinar nas Escolas de Aprendizes Artífices. Isso solicitou uma demanda de novas expertises voltadas para o ensino profissional. No caso destas Escolas, a expertise foi definida a partir de João Luderitz e sua equipe de técnicos compostos, em sua maioria, por profissionais de origem do Instituto de Parobé, tida como referência de ensino profissional em todo o País. Este instituto antes mesmo das EAAs já havia sofrido uma reformulação no ensino, a partir das experiências adquiridas por João Luderitz em sua viagem pela Europa e Estados Unidos. Esta reforma elevou o status de ensino deste Instituto.

Como foi dito, os saberes para ensinar e saberes a ensinar estão associados a saberes presentes nas instituições de ensino na forma de 
prescrições e que, de alguma forma, possuem valor social, propósito e finalidades bem definidas, tornando-se saberes objetivados. Por meio dos relatórios do Serviço de Remodelação do Ensino Profissional Técnico constataram-se movimentos de institucionalização de saberes a ensinar e saberes para ensinar aritmética que permitiram a compreensão de sua legitimação, ou ainda, de suas referências.

As referências para a institucionalização dos saberes para ensinar e saberes a ensinar aritmética estão apoiadas na expertise de João Luderitz e sua equipe que compõe o Serviço de Remodelação. Para a escolha e definição dos saberes a ensinar aritmética das Escolas de Aprendizes Artífices, João Luderitz se apoiou em sua experiência de reforma do Instituto Profissional Técnico de Porto de Alegre, que, por sua vez, tinha como referências o modelo de ensino técnico secundário americano.

O ensino de aritmética foi dividido em duas disciplinas: "Contas", constituída de saberes a ensinar voltados para uma formação geral junto com a alfabetização, e "Arithmética", constituída de saberes a ensinar para uma formação de cunho prático, fornecendo elementos para resolver problemas associados à economia das oficinas por influência de Luderitz.

A instituição dos saberes para ensinar das Escolas de Aprendizes Artífices se apresenta de forma velada nas prescrições sugeridas pelo Serviço de Remodelação. A partir das obras sugeridas pela comissão que era responsável para avaliação e adoção de compêndios, é possível observar um padrão. Dentre as obras sugeridas para o ensino de aritmética, boa parte fundamentava-se no método intuitivo, método este de ensino amplamente difundido nos Grupos Escolares de diversos estados brasileiros. Este silêncio quanto à clara prescrição do método pedagógico a ser adotado pelas EAAs nos documentos normativos, é um indicativo de que, apesar de haver uma adoção do método intuitivo a partir das obras, ainda há a presença de saberes para ensinar que devem ser considerados.

A reforma promovida pelo Serviço de Remodelação foi um processo verticalizado, de cima para baixo, ou seja, de forma imperativa, em que todas as Escolas de Aprendizes Artífices tiveram que adotá-la. No caso da Escola de Aprendizes Artífices de Santa Catharina é possível verificar 
dificuldades quanto às mudanças ocorridas. Contudo, ainda assim, o edital de compra de livros em concordância com as orientações demonstra o esforço desta instituição em implementar as modificações indicadas.

\section{Referências}

ALMEIDA, A. V. Da Escola de Aprendizes Artífices ao Instituto Federal de Santa Catarina. Florianópolis: Publicações do IF-SC, 2010.

BRASIL. Decreto $n^{0}$ 7.566, de 23 de setembro de 1909. Cria nas Capitais dos Estados da República Escolas de Aprendizes Artífices para o ensino profissional primário e gratuito. 1909a. Disponível em: <https://repositorio.ufsc.br/handle/123456789/116790>. Acesso em: 16 dez. 2017.

BRASIL. Decreto $n^{0}$ 7.649, de 11 de novembro de 1909. Cria nas Escolas de Aprendizes Artífices os lugares de professores dos cursos primários noturnos e de desenho. 1909b. Disponível em: <https://repositorio.ufsc.br/handle/123456789/116789>. Acesso em: 16 dez. 2017.

BRASIL. Decreto ${ }^{\circ} 7.763$ de 23, de dezembro de 1909. Altera os decretos de $n^{\circ}$ 7.566 e 7.649. 1909c. Disponível em: <https://repositorio.ufsc.br/xmlui/handle/123456789/182545>. Acesso em: 16 dez. 2017.

BRASIL. Decreto ${ }^{\circ}$ 13.064, de 12 de junho de 1918. Dá novo regulamento às Escolas de Aprendizes Artífices. 1918a. Disponível em: <https://repositorio.ufsc. br/xmlui/handle/123456789/182547>. Acesso em: 16 dez. 2017.

BRASIL. Ministério da Agricultura, Industria e Comércio. Relatório das Escolas de Aprendizes Artífices: 1918. 1918b. Disponível em: <https://repositorio.ufsc.br/ xmlui/handle/123456789/181798>. Acesso em: 16 dez. 2017.

BRASIL. Ministério da Agricultura, Industria e Comércio. Relatório das Escolas de Aprendizes Artífices: 1920. 1920. Disponível em: <https://repositorio.ufsc.br/ xmlui/handle/123456789/182543>. Acesso em: 16 dez. 2017. 
BRASIL. Ministério da Agricultura, Industria e Comércio. Relatório das Escolas de Aprendizes Artífices: 1922. 1922. Disponível em: <https://repositorio.ufsc.br/ xmlui/handle/123456789/182554>. Acesso em: 16 dez. 2017.

BRASIL. Ministério da Agricultura, Industria e Comércio. Relatório das Escolas de Aprendizes Artífices: 1924. 1924. Disponível em: <https://repositorio.ufsc.br/ xmlui/handle/123456789/182548>. Acesso em: 16 dez. 2017.

BRASIL. Ministério da Agricultura, Industria e Comércio. Relatório das Escolas de Aprendizes Artífices: 1925. 1925. Disponível em: <https://repositorio.ufsc.br/ xmlui/handle/123456789/182551> . Acesso em: 16 dez. 2017.

BRASIL. Ministério da Agricultura, Industria e Comércio. Relatório das Escolas de Aprendizes Artífices: 1926. 1926. Disponível em: <https://repositorio.ufsc.br/ xmlui/handle/123456789/182544>. Acesso em: 16 dez. 2017.

BRASIL. Ministério da Agricultura, Indústria e Comércio. Escola de Aprendizes Artífices de Santa Catarina Relatório de gestão do Diretor Heitor Blum em 1917. 1917. Disponível em: <https://repositorio.ufsc.br/xmlui/handle/123456789/177358>. Acesso em: 16 dez. 2017.

CHERVEL, A. História das disciplinas escolares: reflexões sobre um campo de pesquisa. Teoria \& Educação, Porto Alegre, v. 2, p. 177-229, 1990.

CINTRA, M. C. O processo de aprendizado do ofício de alfaiate em Florianópolis (1913-1968). 146 f. Dissertação (Mestrado em Educação) - Universidade Federal de Santa Catarina, Florianópolis, 2004.

CHOPPIN, A. O historiador e o livro escolar. Trad. Maria Helena Camara Bastos. História da Educação, Rio Grande do Sul, v. 6, n. 11, p. 5-24, jan./jun. 2002.

COSTA, D. A.; VALENTE, W. R. O repositório de conteúdo digital nas pesquisas de história da educação matemática, RIDPHE_R - Revista Iberoamericana do Patrimônio Histórico-Educativo, Campinas, v. 1, n. 1, p. 96-110, jul./dez. 2015. CUNHA, L. A. O ensino de ofício nos primórdios da industrialização. São Paulo: Editora UNESP, 2000. 
FONSECA, C. S. História do ensino industrial. Rio de Janeiro: Escola Técnica Nacional, 1961. v. 1.

FARIA FILHO, L. M.; GONÇALVES, I. A.; VIDAL, D. G.; PAULILO, A. L. A cultura escolar como categoria de análise e como campo de investigação na história da educação brasileira. Educação e Pesquisa, São Paulo, v. 30, n. 1, p. 139-159, jan./abr. 2004.

HOFSTETTER, R.; SCHNEUWLY, B. Saberes: um tema central para as profissões do ensino e da formação. In: HOFSTETTER, R.; VALENTE, W. R. (Org.). Saberes em (trans) formação: tema central a formação de professores. 1. ed. São Paulo: Editora da Física, 2017. p. 113-172.

HOFSTETTER, R.; SCHNEUWLY, B.; FREYMOND, M. "Penetrar na verdade da escola para ter elementos concretos de sua avaliação" - A irresistível institucionalização do expert em educação (século XIX e XX). In: HOFSTETTER, R. VALENTE, W. R. (Org.). Saberes em (trans) formação: tema central a formação de professores. 1. ed. São Paulo: Editora da Física, 2017. p. 55-112.

JULIA, D. A cultura escolar como objeto histórico. Trad. Gizele de Souza. Revista Brasileira de História da Educação, Campinas, v. 1, n. 1, p. 9-43, jan./jun. 2001.

KUHN, T. T; FLORES, C. R. O ensino de desenho para o trabalho industrial: o traçado de uma pesquisa histórica. In: ENCONTRO NACIONAL DE PESQUISA EM HISTÓRIA DA EDUCAÇÃO MATEMÁTICA, 3., 2016, São Matheus-ES. Anais... São Matheus-ES, 2016. p. 342-349. Disponível em: <https://repositorio.ufsc.br/ xmlui/handle/123456789/171651>. Acesso em: 15 jan. 2018.

KONDER, A. Discursos da $1^{a}$ Conferência de Ensino Primário. Santa Catarina, jul./ago. 1927. Disponível em: <https://repositorio.ufsc.br/xmlui/handle/123456789/132521>. Acesso em: 16 dez. 2017.

MANFREDI, S. M. Educação Profissional no Brasil. São Paulo: Cortez Editora, 2002.

MARQUES, S. S. L. Práticas de in(ex)clusão: o currículo da Escola de Aprendizes Artífices de Santa Catarina (1909-1922). 188 f. Dissertação (Mestrado em Educação) - Universidade Regional de Blumenau, Blumenau, 2012. 
MATHIESON, L. C. Vozes impressas: a Reforma de 1920 em pauta na imprensa paulista. 2017. 246 f. Tese (Doutorado em Educação) — Faculdade de Educação da Universidade de São Paulo, São Paulo, 2017.

NAGLE, J. Educação e sociedade na Primeira República. 2. ed. São Paulo: Editora Pedagógica e Universitária, 1976.

OLIVEIRA, M. A. Antônio Bandeira Trajano e o método intuitivo para o ensino de Arithmetica (1879-1954). 2013. 142 f. Dissertação (Mestrado em Educação) Universidade Tiradentes, Aracaju, 2013.

PEREIRA, B. M. A Educação Escolarizada Para o Trabalho no Início do Século XX: As Escolas de Aprendizes Artífices. In: ENCONTRO REGIONAL (ANPUH-MG) 'DIMENSÕES DO PODER NA HISTÓRIA', 28., 2012, Mariana-MG. Anais... Mariana-MG, 2012. Disponível em: <http://www.encontro2012.mg.anpuh.org/resources/anais/24/1340284884_ARQUIVO_ TEXTOCOMPLETOBERNADETTHMARIAPEREIRA.pdf >. Acesso em: 28 dez. 2017.

QUELUZ, G. L. Concepções de Ensino Técnico na República Velha (1909-1930). Curitiba: CEFET-PR, 2000.

QUELUZ, G. L. Método Intuitivo e o Serviço de Remodelação do Ensino Profissional Técnico. Revista Educação \& Tecnologia, Curitiba, v. 3, p. 96-114, 1998.

VALENTE, W. R. Livro didático e educação matemática: uma história inseparável. Zetetiké, Campinas, v. 16, n. 30, p. 139-162, jul./dez. 2008.

VALENTE, W. R. História da educação matemática nos anos iniciais: a passagem do simples/complexo para o fácil/difícil. Cadernos de História da Educação (Online), v. 14, p. 357-367, 2015.

SANTA CATARINA. Mensagem apresentada ao Congresso Representativo do Estado pelo governador Vidal José de Oliveira Ramos em 23 de julho de 1912. Florianópolis: Typ. d'O Dia, 1912. Disponível em: <https://repositorio.ufsc.br/xmlui/handle/123456789/177029>. Acesso em: 15 jan. 2018.

SOARES, M. J. As Escolas de Aprendizes Artífices: estrutura e evolução. Fórum Educacional, Rio de Janeiro, v. 6, n. 2, p. 58-92, jul./set. 1982. 
TRAJANO. A. Arithmetica Elementar Illustrada. 92. ed. Rio de Janeiro: Livraria Francisco Alves, 1922. Disponível em:<https://repositorio.ufsc.br/handle/123456789/105107>. Acesso em: 16 dez. 2017.

TRINDADE, D. A. O medir na aritmética intuitiva de Olavo Freire (1911): intuitivo? In: SEMINÁRIO TEMÁTICO SABERES ELEMENTARES MATEMÁTICOS DO ENSINO PRIMÁRIO (1890-1970): Sobre o que tratam os Manuais Escolares?, 14., 2016, Natal. Anais... Natal, 2016. Disponível em: <http://xivseminariotematico. paginas.ufsc.br/files/2016/05/TRINDADE_T2_vf.pdf>. Acesso em: 28 dez. 2017.

Recebido: 29/01/2018

Received: 01/29/2018

Recibido: 29/01/2018

Aprovado: 24/07/2018 Approved: 07/24/2018 Aprobado: 24/07/2018 